\title{
APLIKASI PEPAK BAHASA JAWA BERBASIS ANDROID
}

\author{
Afit Muhammad Lukman ${ }^{1}$, Anggy Dwi Setyo Wibowo ${ }^{2}$ \\ ${ }^{1}$ Sistem Informasi, Universitas Bina Sarana Informatika Indonesia \\ ${ }^{2}$ Teknik Komputer, Universitas Bina Sarana Informatika Indonesia \\ e-mail:afit.fml@bsi.ac.id ${ }^{1}$,anggydwi86@gmail.com ${ }^{2}$
}

\begin{abstract}
Basically smartphones are designed to meet human needs in communicating over long distances to be more efficient. Utilization of this technology is used for the purposes of various fields with applications that can support its use. To make it easier for users in the learning process of Javanese language and culture, an application is needed that provides benefits and adds insight to the user so that it is expected to be able to provide actual information about vocabulary and learning procedures. The research method used is quantitative and qualitative. Which focuses more on observation and literature study. This research unit is the general public, especially the people of Kramat Village, Karangmoncol District, Purbalingga Regency. From the results of field observations, the respondents gave a good response to the use of this Android-based educational application in everyday life. Furthermore, this android based educational application has a positive and significant impact on users in the learning process of Javanese language and culture. The impact is greater simultaneously than partially. Therefore, it can be concluded that the existence of this android-based educational application really helps users in the process of learning Javanese language and culture
\end{abstract}

\section{Keywords: Smartphone, Android, java language and culture}

Abstrak - Pada dasarnya smartphone dirancang untuk memenuhi kebutuhan manusia dalam berkomunikasi jarak jauh agar lebih efisien. Pemanfaatan dari teknologi tersebut digunakan untuk keperluan berbagai bidang dengan aplikasi yang dapat mendukung penggunanaya. Untuk mempermudah pengguna dalam proses pembelajaran bahasa dan budaya Jawa maka diperlukan aplikasi yang memberi manfaat serta menambah wawasan bagi pengguna sehingga diharapkan mampu memberikan informasi yang aktual tentang kosakata serta tata cara mempelajarinya. Metode penelitian yang dilakukakn adalah bersifat kuantitatif dan kualitatif. Yang lebih menitik bertakan pada observasi dan studi pustaka. Unit penelitian ini adalah masyarakat umum khususnya masyarakat Desa Kramat Kecamatan Karangmoncol Kabupaten Purbalingga. Dari hasil observasi dilapangan mengemukakan responden memberikan respon yang baik terhadap penggunaan aplikasi edukasi berbasis android ini pada kehidupan seharihari. Selanjutnya aplikasi edukasi berbasis android ini berdampak positif dan signifikan terhadap pengguna dalam proses belajar bahasa dan budaya Jawa. Dampak secara simultan lebih besar dibandingkan secara parsial. Maka dari itu bisa ditarik kesimpulan bahwa keberadaan aplikasi edukasi berbasis android ini sangat membantu pengguna dalam Proses belajar bahasa dan budaya Jawa.

Kata kunci: Smartphone, Android, Bahasa dan Budaya Jawa 


\section{PENDAHULUAN}

Untuk saat ini teknologi informasi semakin mempermudah manusia untuk menyajikan informasi, kini dengan pesatnya perkembangan teknologi kita dapat menyajikan informasi dengan media yang beragam, salah satunya dengan memanfaatkan teknologi yang sudah banyak diminati ataupun dimiliki masyarakat yaitu smartphone dengan sistem operasi android.

Pada dasarnya smartphone dirancang untuk memenuhi kebutuhan manusia dalam berkomunikasi jarak jauh agar lebih efisien. Dalam perkembangannya, fungsi dari smartphone itu sendiri bukan sekedar sebagai alat untuk komunikasi jarak jauh, melainkan sebagai media penyimpanan informasi, edukasi, hiburan, serta pencarian informasi. Pemanfaatan dari teknologi tersebut digunakan untuk keperluan berbagai bidang dengan aplikasi yang dapat mendukung penggunanaya.

Bahasa Jawa merupakan salah satu dari ragam bahasa yang ada di Negara Indonesia. Seperti bahasa lain, bahasa Jawa juga memiliki tata cara atau aturan yang mengatur bagaimana cara penulisan dan pengucapan kata dengan baik. Jika dilihat kondisi saat ini masih banyak orang yang masih belum atau bahkan tidak berminat untuk mempelajari bahasa daerah khususnya bahasa Jawa. Hal tersebut dikarenakan semakin turunnya pemakaian bahasa daerah pada kalangan masyarakat serta cara penyampaian dalam pembelajaran disekolah yang terkesan statis. Agar dapat melestarikan bahasa dan budaya Jawa, penting bagi kita untuk selalu membiasakan berbahasa Jawa dalam kegiatan sehari-hari. Hal ini dapat kita pelajari melalui aplikasi berbasis android, dengan alasan agar anak-anak, remaja, maupun dewasa menjadi lebih tertarik untuk menggunakannya.

\section{TINJAUAN PUSTAKA}

a. Aplikasi Mobile

Aplikasi yang digunakan secara berpindah-pindah tempat (mobile) sehingga pengguna dapat menggunakan sesering mungkin tanpa mengganggu aktifitas yang dikerjakan (Wahana Komputer, 2014).

\section{b. Android}

Menurut (Kusniyati \& Pangondian Sitanggang, 2016) menyimpulkan bahwa "android merupakan sistem operasi berbasis linux untuk perangkat mobile seperti smartphone dan komputer tablet".

Basis sistem android yaitu kernel linux. Android pada mulanya didirikan oleh Andy Rubin, Rich Miner, Nick Sears, dan Chris White pada tahun 2003.

\section{c. Metode Pembelajaran}

Menurut Kamus Besar Bahasa Indonesia (KBBI) belajar adalah tingkah laku atau tanggapan yang disebabkan oleh pengalaman, berlatih, dan berusaha memperoleh kepandaian atau ilmu. Sedangkan pembelajaran merupakan proses, cara, perbuatan untuk menjadikan orang atau makhluk hidup belajar.

Dari penjelasan tersebut kita bisa menyimpulkan bahwa sebenarnya untuk membuat diri kita berilmu atau pandai memerlukan usaha dan cara belajar yang efektif dan efisien tanpa membuat aktifitas kita terganggu. Dengan semakin berkembangnya teknologi untuk sekarang ini maka aplikasi mobile adalah pilihan yang tepat untuk dimanfaatkan sebagai pegangan dalam kita belajar. Agar aplikasi mobile dapat dimanfaatkan secara baik untuk proses pembelajaran, diperlukan juga aplikasi edukasi yang memahami kebutuhan dalam proses belajar dan mengajar.

\section{d. B4A (Basic Four Android)}

B4A merupakan peralatan RAD (Rapid Application Development) yang berintegritas dengan java dan android SDK untuk mempermudah developer dalam mengembangkan aplikasi android (Actual Training, 2013). 


\section{e. Bahasa Pemrograman BASIC}

Bahasa BASIC merupakan salah satu bahasa pemrograman yang memiliki tujuan sebagai bahasa awam antara pengguna komputer yang langsung berinteraksi dengan komputer (Limpingen Soft Comporation, 2015).

BASIC merupakan singkatan dari Beginner's All purpose Symbolic Intruction Code ditemukan oleh John G. Kemeny, profesor dari Darthmouth ColleSSge dan Thomas E. Kurtz pada tahun 1960. Perintah-perintah dalam bahasa BASIC relatif sangat mudah dipahami, bahkan sampai orang yang awam sekalipun. Seiring berjalannya waktu bahasa BASIC kemudian dikembangkan dengan pemrograman yang lebih terstruktur, dengan tujuan untuk menghindari perintah GOTO yang menyebabkan program menjadi sukar dipahami alurnya.

\section{f. UML (Unified Modeling Language)}

Menurut (Utomo et al., 2015) menyatakan bahwa "UML merupakan sebuah bahasa yang berdasarkan grafik atau gambar dapat menentukan dan mendokumentasikan sepotong informasi yang terdapat dalam software".

\section{g. HTML (Hypertext Markup Language)}

HTML merupakan salah satu dari beberapa bahasa pemrograman yang digunakan untuk membuat halaman web, antara lain menampilkan informasi didalam sebuah web internet yang ditulis kedalam format ASCII agar dapat menghasilkan tampilan yang terintegrasi (Harison \& Syarif, 2016)

File HTML berisi instruksi tertentu yang dapat memberikan suatu format dokumen yang akan ditampilkan pada World Wide Web. Dengan bahasa HTML sistem komputer yang berbeda antara satau dengan yang lainya dapat mengenali format-format yang ditampilkan dalam situs-situs internet tanpa perbedaan yang berarti.

\section{h. SQLite}

Menurut (Kusniyati \& Pangondian Sitanggang, 2016) menyimpulkan bahwa "SQLite merupakan basis data relasional yang bersifat ACID (Atomicity, Consistency, Isolation Durability) yang memiliki ukuran pustaka kode yang relative kecil dan ditulis dalam bahasa C".

\section{i. Flowchart}

Menurut (Harison \& Syarif, 2016) menyatakan bahwa "flowchart merupakan urutan proses dalam sistem yang terdiri dari bagan-bagan dengan simbol-simbol tertentu yang menggambarkan langkahlangkah penyelesaian suatu masalah".

\section{j. HIPO (Hierarchy Input Process Output)}

HIPO adalah alat bantu untuk membuat spesifikasi program yang dapat digunakan untuk mengkomunikasikan spesifikasi sitem kepada programmer melalui proses perancangan (Nugroho et al., 2017)

\section{k. Black Box Testing}

Menurut (Kusniyati \& Pangondian Sitanggang, 2016) menyatakan bahwa "metode uji coba black box memfokuskan pada keperluan fungsional dari software tanpa menguji desain maupun kode program".

\section{METODE PENELITIAN}

Metode pertama yang digunakan adalah obeservasi yang dilakukan dengan cara melakukan pengamatan atau peninjauan secara langsung mengenai kondisi lingkungan tempat tinggal guna mendapatkan informasi dari objek yang dijadikan sebagai bahan penelitian, agar hasil yang didapatkan akurat.

Metode yang digunakan selanjutnya adalah studi pustaka yang dilakukan dengan Pengumpulan data yang bersumber dari berbagai buku yang menjadi referensi penulisan jurnal ini dan pencarian dengan media internet untuk menunjang 
pemecahan permasalahan yang tidak didapatkan dalam penelitian serta untuk memperoleh data-data tambahan.

\section{HASIL DAN PEMBAHASAN}

Rencana pembuatan aplikasi ini dimaksudkan untuk membuat metode pembelajaran bahasa dan budaya jawa yang dapat berjalan pada sistem operasi android berbasis mobile. Sehingga user dapat mempelajari tata cara berbahasa dan budaya jawa hanya dengan menggunakan smartphone yang dimiliki pengguna.

\section{a. Rancangan Program}

Rancangan awal dalam aplikasi ini adalah sebagai berikut:

1. Pada aplikasi ini terdapat 4 menu utama yaitu menu kawruh basa, menu aksara jawa, menu wayang purwa, dan menu about.

2. Menu kawruh basa dapat digunakan user untuk mempelajari berbagai macam penamaan, istilah, dan kosakata bahasa jawa.

3. Menu aksara jawa dapat digunakan user untuk belajar menulis huruf dan angka jawa (aksara) beserta tanda bacanya (sandangan).

4. Menu wayang purwa dapat digunakan user untuk mengetahui nama-nama tokoh pewayangan beserta julukan masing-masing tokohnya.

5. Menu about dapat digunakan user untuk mengetahui profil pembuat aplikasi ini.

6. Aplikasi ini dibuat untuk memudahkan user dalam mempelajari bahasa dan budaya jawa dalam kehidupan sehari-hari.

\section{b. Spesifikasi File}

File yang digunakan dalam aplikasi ini bertujuan untuk menampilkan berbagai macam materi yang telah disediakan seperti materi kawruh basa, aksara jawa, dan wayang purwa. Terdiri dari 2 jenis file yaitu file database dan file html, berikut spesifikasinya.
File database tabel materi yang akan dipilih

Nama File

: ayo

Fungsi : Untuk menyimpan daftar materi masing-masing fitur.

Tipe File : File master database

Software : SQLite

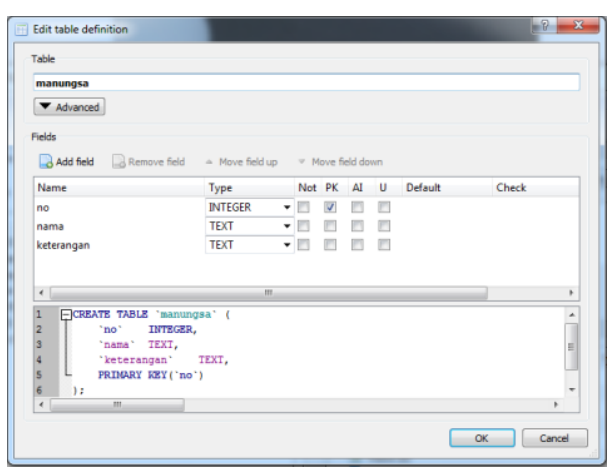

Sumber: Hasil Penelitian

a. Spesifikasi file html

Nama File : wilangankawi

Fungsi : Menampilkan materi

Tipe File : File html

Software : Notepad

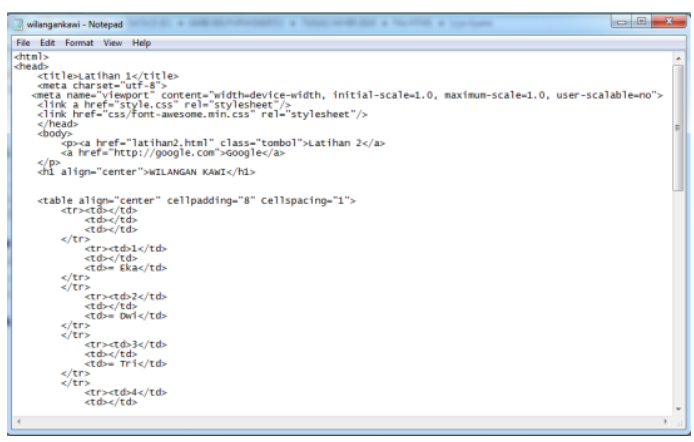

Sumber: Hasil Penelitian 


\section{c. HIPO.}

Hierarchy Input Process Output dari aplikasi Pepak Bahasa Jawa adalah sebagai berikut:

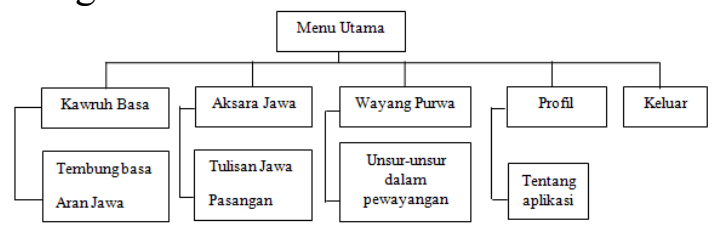

\section{d. Flowchart}

\section{Flowchart Menu Utama}

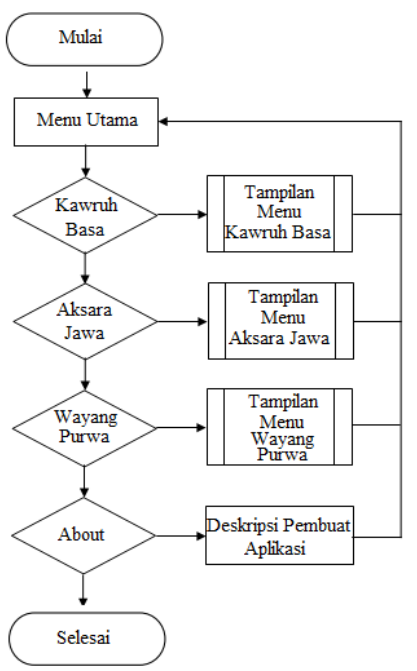

Keterangan:

Di dalam menu utama terdapat menu materi (kawruh basa, aksara jawa, dan wayang purwa), menu about yang berisi informasi pembuat aplikasi, dan menu exit untuk keluar dari aplikasi tersebut.

\section{Flowchart Menu Materi}

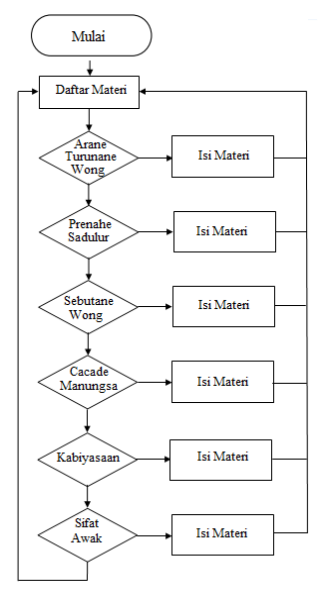

\section{Keterangan:}

Pada menu daftar materi pengguna dapat memilih materi yang akan dipelajari, dan secara langsung materi akan muncul sesuai pilihan pengguna.

\section{e. User Interface}

Rancangan pembuatan desain program:

1. Menu Utama

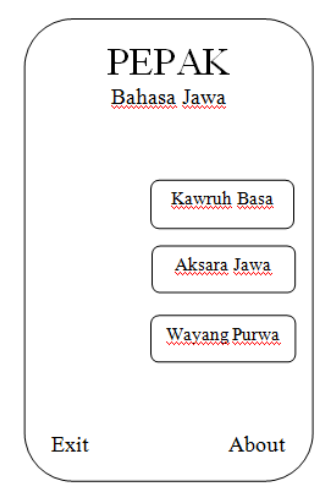

Menu utama ini terdapat 5 tombol atau pilihan yang masingmasing memiliki fungsinya sendiri guna memudahkan pengguna untuk menggunakan aplikasi Pepak Bahasa Jawa. Ada 3 menu yang digunakan untuk proses belajar ahasa dan budaya Jawa yaitu Kawruh basa (terdapat berbagai macam kosakata dalam bahasa jawa), Aksara Jawa (belajar menulis dengan aksara atau huruf jawa), Wayang Purwa (mengenal tokoh atau karakter dalam pewayangan). Selanjutnya ada menu about (berisi tentang informasi pembuat aplikasi Pepak Bahasa Jawa ini), dan exit (digunakan pengguna untuk keluar dari aplikasi). 
2. Menu Materi 1

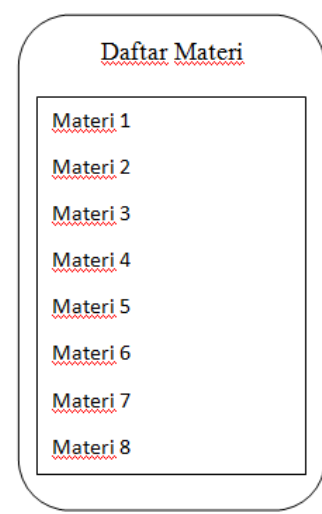

Menu ini berisi tentang materi pembelajaran bahasa dan budaya jawa. Dalam menu ini penulis dapat memilih materi yang akan di pelajari, yang mana materi itu terbagi menjadi 2 kelompok yaitu kawruh basa dan wayang purwa. Masing-masing dari materi kawruh basa dan wayang purwa terdapat 6 sampai 8 sub materi yang dapat pengguna pilih untuk dipelajari.

\section{Menu Materi 2}

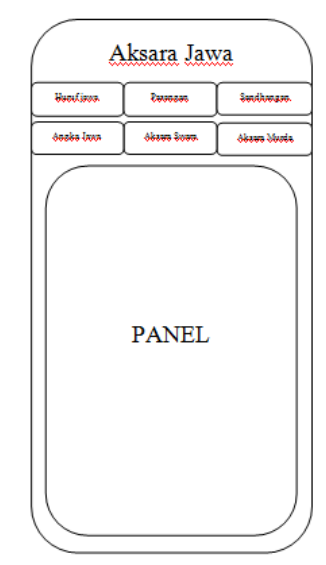

Dalam menu ini terdapat 6 tombol materi yang akan berfungsi untuk menampilkan materi tentang aksara jawa yaitu huruf jawa, pasangan, sandhangan, angka jawa, aksara swara, aksara murda. Setiap materi atau tombol yang pengguna pilih atau akses secara otomatis akan tampil pada panel di menu ini.
4. Menu Isi Materi

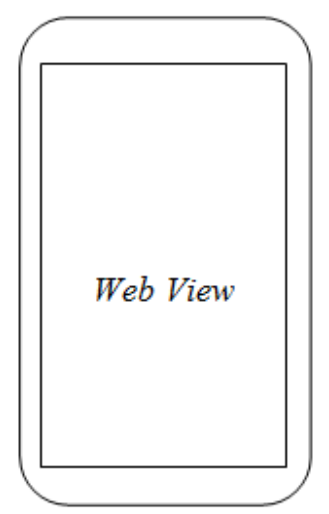

Menu ini berisi tentang pembahasan dari materi yang pengguna pilih pada menu materi kawruh basa dan wayang purwa. Pembahasan dari materi yang pengguna pilih akan muncul dalam menu ini.

\section{f. Implementasi}

Hasil dari rancangan design program yang telah dibuat dapat kita implementasikan sebagai berikut:

1. Menu Utama

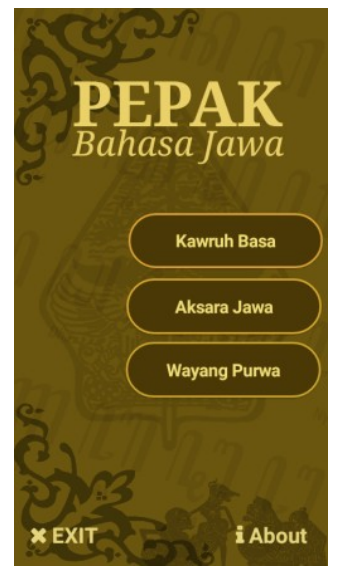


2. Menu Materi 1

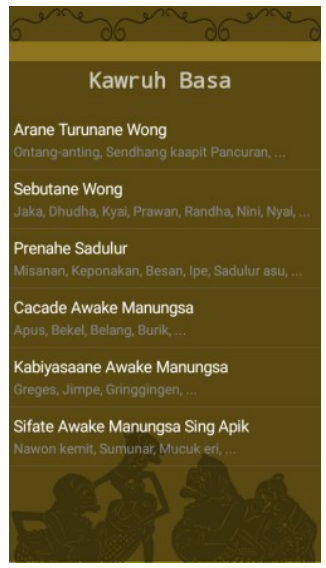

3. Menu Materi 2

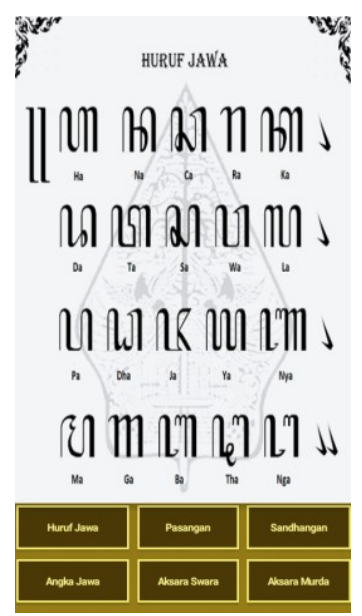

4. Menu Isi Materi

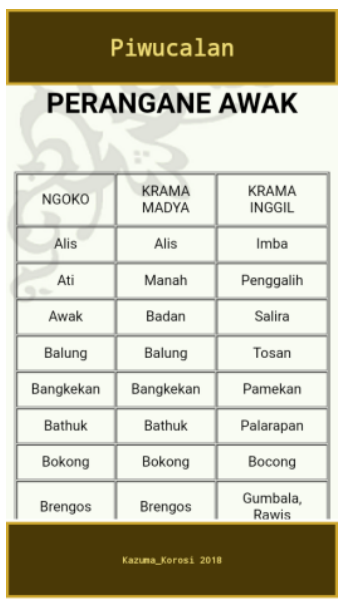

\section{g. Pengujian Unit}

Pengujian ini dilakukan dengan menggunakan metode Black Box Testing. Berikut hasil pengujiannya:

\begin{tabular}{|c|c|c|c|c|}
\hline No & $\begin{array}{c}\text { Ranca } \\
\text { ngan } \\
\text { Proses }\end{array}$ & $\begin{array}{c}\text { Hasil } \\
\text { Yang } \\
\text { Diharap } \\
\text { kan }\end{array}$ & Hasil & $\begin{array}{c}\text { Keteran } \\
\text { gan }\end{array}$ \\
\hline 1 & $\begin{array}{l}\text { Klik } \\
\text { huruf } \\
\text { jawa }\end{array}$ & $\begin{array}{l}\text { Akan } \\
\text { muncul } \\
\text { materi } \\
\text { mengen } \\
\text { ai huruf } \\
\text { jawa }\end{array}$ & Sesuai & Lancar \\
\hline 2 & $\begin{array}{l}\text { Klik } \\
\text { pasang } \\
\text { an }\end{array}$ & $\begin{array}{l}\text { Akan } \\
\text { muncul } \\
\text { materi } \\
\text { mengen } \\
\text { ai } \\
\text { pasanga } \\
\text { n dari } \\
\text { huruf- } \\
\text { huruf } \\
\text { jawa }\end{array}$ & Sesuai & Lancar \\
\hline 3 & $\begin{array}{l}\text { Klik } \\
\text { sandha } \\
\text { ngan }\end{array}$ & $\begin{array}{l}\text { Akan } \\
\text { muncul } \\
\text { materi } \\
\text { mengen } \\
\text { ai } \\
\text { sandha } \\
\text { ngan } \\
\text { (tanda } \\
\text { baca) } \\
\text { huruf } \\
\text { jawa }\end{array}$ & Sesuai & Lancar \\
\hline 4 & $\begin{array}{l}\text { Klik } \\
\text { aksara } \\
\text { murda }\end{array}$ & $\begin{array}{l}\text { Akan } \\
\text { muncul } \\
\text { materi } \\
\text { mengen } \\
\text { ai } \\
\text { aksara } \\
\text { murda }\end{array}$ & Sesuai & Lancar \\
\hline 5 & $\begin{array}{l}\text { Klik } \\
\text { aksara } \\
\text { swara }\end{array}$ & $\begin{array}{l}\text { Akan } \\
\text { muncul } \\
\text { materi } \\
\text { mengen } \\
\text { ai } \\
\text { aksara }\end{array}$ & Sesuai & Lancar \\
\hline
\end{tabular}




\begin{tabular}{|l|l|l|l|l|}
\hline & & $\begin{array}{l}\text { swara } \\
\text { (huruf } \\
\text { vokal) }\end{array}$ & & \\
\hline 6 & $\begin{array}{l}\text { Klik } \\
\text { angka } \\
\text { jawa }\end{array}$ & $\begin{array}{l}\text { Akan } \\
\text { muncul } \\
\text { materi } \\
\text { mengen } \\
\text { ai } \\
\text { angka } \\
\text { jawa }\end{array}$ & Sesuai & Lancar \\
\hline
\end{tabular}

\section{KESIMPULAN}

Perancangan serta pembuatan aplikasi ini merupakan salah satu aplikasi edukasi yang berguna untuk mempelajari bahasa dan budaya jawa. Aplikasi ini dibuat dengan menggunakan bahasa pemrograman basic dengan software B4A, untuk tampilan materi menggunakan file html.

Dengan perkembangan zaman yang sudah berkembang, maka perlu adanya perkembangan juga dalam proses belajar. Dengan aplikasi ini pengguna dapat dengan mudah dalam mempelajari bahasa dan budaya jawa, hal ini dikarenakan aplikasi Pepak Bahasa Jawa ini berbentuk mobile yang dapat diakses melalui smartphone yang pengguna miliki.

\section{DAFTAR PUSTAKA}

Harison, \& Syarif, A. (2016). SISTEM INFORMASI GEOGRAFIS PEMETAAN SARANA

PRASARANA Jurnal TEKNOIF ISSN : 2338-2724. Jurnal TEKNOIF.

Kusniyati, H., \& Pangondian Sitanggang, N. S. (2016). APLIKASI EDUKASI BUDAYA TOBA SAMOSIR BERBASIS ANDROID. JURNAL TEKNIK INFORMATIKA. https://doi.org/10.15408/jti.v9i1.5573

Kamus Besar Bahasa Indonesia (KBBI).

Nugroho, D. A., Harmastuti, \& Uminingsih. (2017). Membangun Game Edukasi "Matematika Maze" Berbasis Android Untuk Meningkatkan Kemampuan Berhitung Pada Anak Sekolah Dasar. Jurnal Statistika Industri Dan Komputasi.

Wahana Komputer. 2014. Membangun Aplikasi Mobile Cross Menggunakan Phonegap. Jakarta: Elex Media Komputindo. 